\title{
NOTES ON THE LIFE HISTORY OF PERIPLANETA FULIGNOSA SERV.
}

\author{
By Phil Rau \\ Kirkwood, Missouri
}

In a lot of Periplaneta americana that came from New Orleans in June 1937, there were three adult females which resembled $P$. americana in size and shape, but the color, instead of being golden-brown, was a dull brownish-black or "off-black." I became suspicious about the species later when the egg-cases began to protrude from their bodies, for they were almost twice the size of those deposited by $P$. americana.

Specimens of the nymphs, which so little resembled either fulignosa or americana, as well as the mother, were sent to Mr. Morgan Hebard, who named them Periplaneta fulignosa Serv. They have been recorded only from southern United States, where they are common in storehouses, docks, etc. He is quite sure that this species, like other members of the genus, is an adventive in America from the old world. He added the note "that the nymphs are so parti-colored that they might have been mistaken for Periplaneta brunnea, another adventive pest, were it not known that they were the immature insects of the adult sent to me."

Four egg-cases were obtained from the three females, and from them hatched 22, 22, 26, and 26 young respectively. This is almost twice the number per egg-case than for its contemporary, $P$. americana.

One female that became adult on June 29 protruded her first egg-case 12 days later, and another egg-case after 11 days. In two cases, notes were made on the period of incubation: one protruding egg-case removed from the mother's body on July 10 gave forth its nymphs August 13; the other egg-case, removed from another mother on June 14, gave forth its young on July 31 , the two having a period of incubation of 35 and 47 days respectively.

The young nymphs ate readily of cinnamon roll, could neatly hollow out a grain of corn, and drank much water. They 
were very lively, ran about the jar rapidly and in their efforts to escape easily walked over the band of vaseline that was spread to prevent their leaving the jar. When they run about they curl up the ends of their abdomens very much like rove beetles; the young of Parcoblatta pennsylvanica, Blatta orientalis, or Periplaneta americana do not have this peculiar behavior.

On hatching, the nymphs are black with white bands on two abdominal segments; the basal segment and one in the middle. Several weeks after hatching I noticed that the first 4 or 5 joints of the antennæ were also white. A month or six weeks later, probably after a moult, the white band on the middle segment became broken so that the center third of it was black. I found still later that both of the white segments in all nymphs in this jar changed to an inconspicuous light brown color while the insect itself was still dull black. On that day I was again surprised to find that in addition to the 4 or 5 segments of white at the tip of the antennæ there was a white portion covering onefourth of the antennæ at its point of attachment. By August 31, they had grown to about one-half inch in length, and when a moult occurred on November 7 , the few that had not died were of a light brown color, resembling very much the half-grown nymphs of $P$. americana.

I do not know if the nymphs I have obtained are pure $P$. fulignosa or hybrids between them and their traveling companions, $P$. americana. If the three females of $P$. fulignosa were trapped in New Orleans just before shipping to St. Louis, it is likely that they mated with their own species, but if they grew up among the americana in the breeding cages of the dealer, from whom I obtained them, it is quite likely that they were fertilized by the males of americana. Then again, they might have been bred in confinement for a number of generations with the result that crossings and re-crossings often may have occurred. The fact, however, that the few roaches which reached middle age became more and more like $P$. americana leads me to believe that the nymphs which Mr. Hebard said could easily be mistaken for $P$. brunnea are not pure stock, but are of hybrid origin, mixed with americana for one or more generations. 

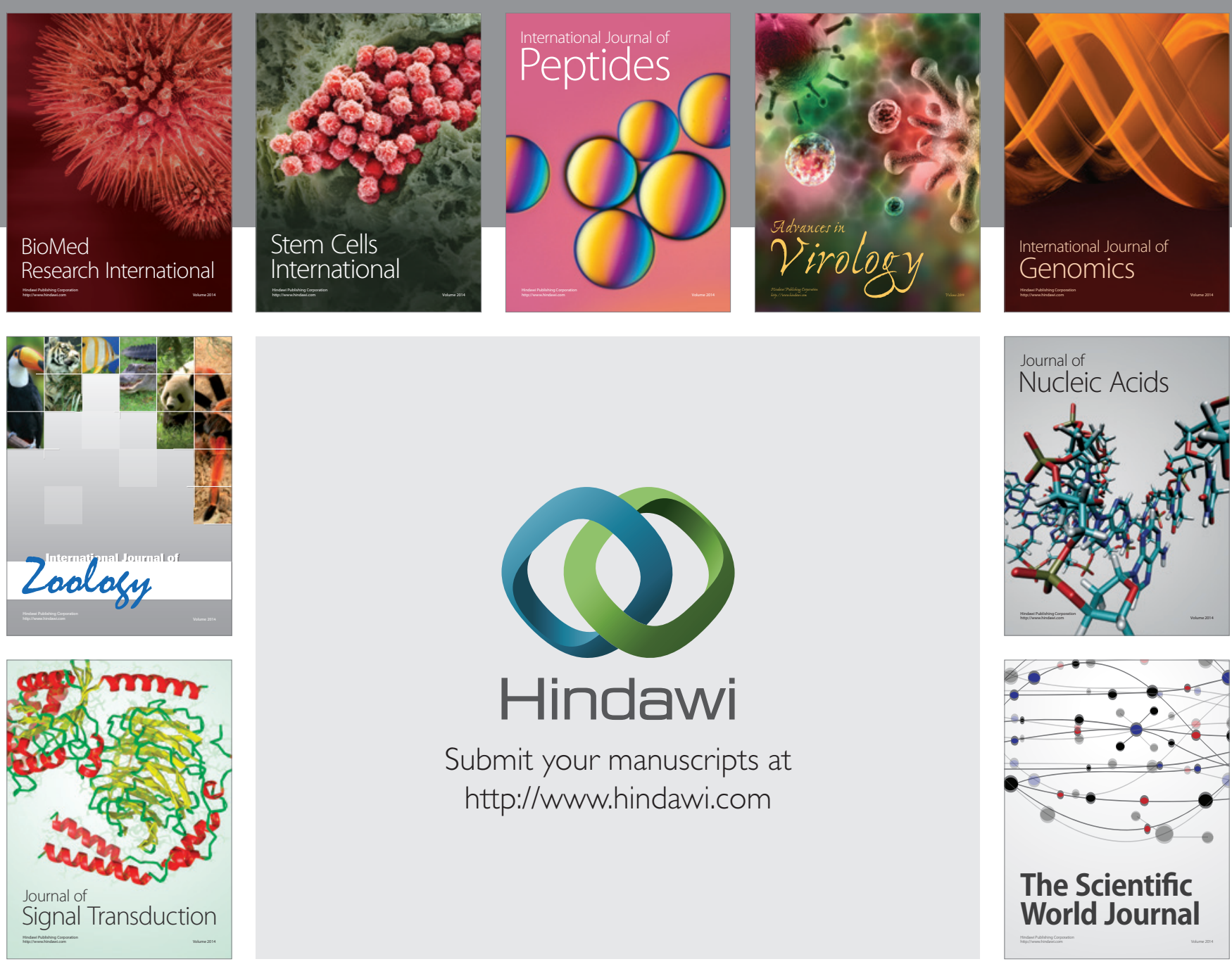

Submit your manuscripts at

http://www.hindawi.com
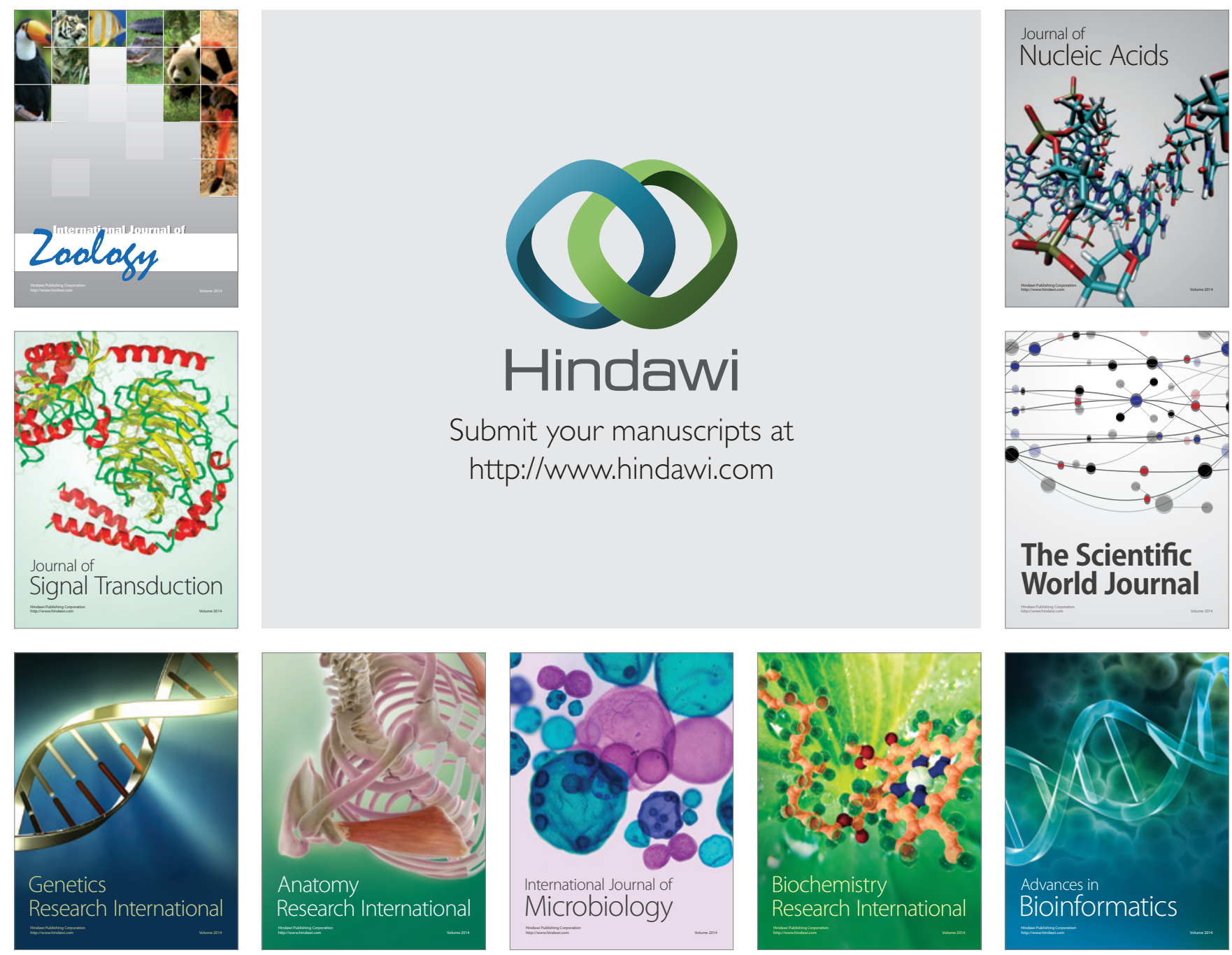

The Scientific World Journal
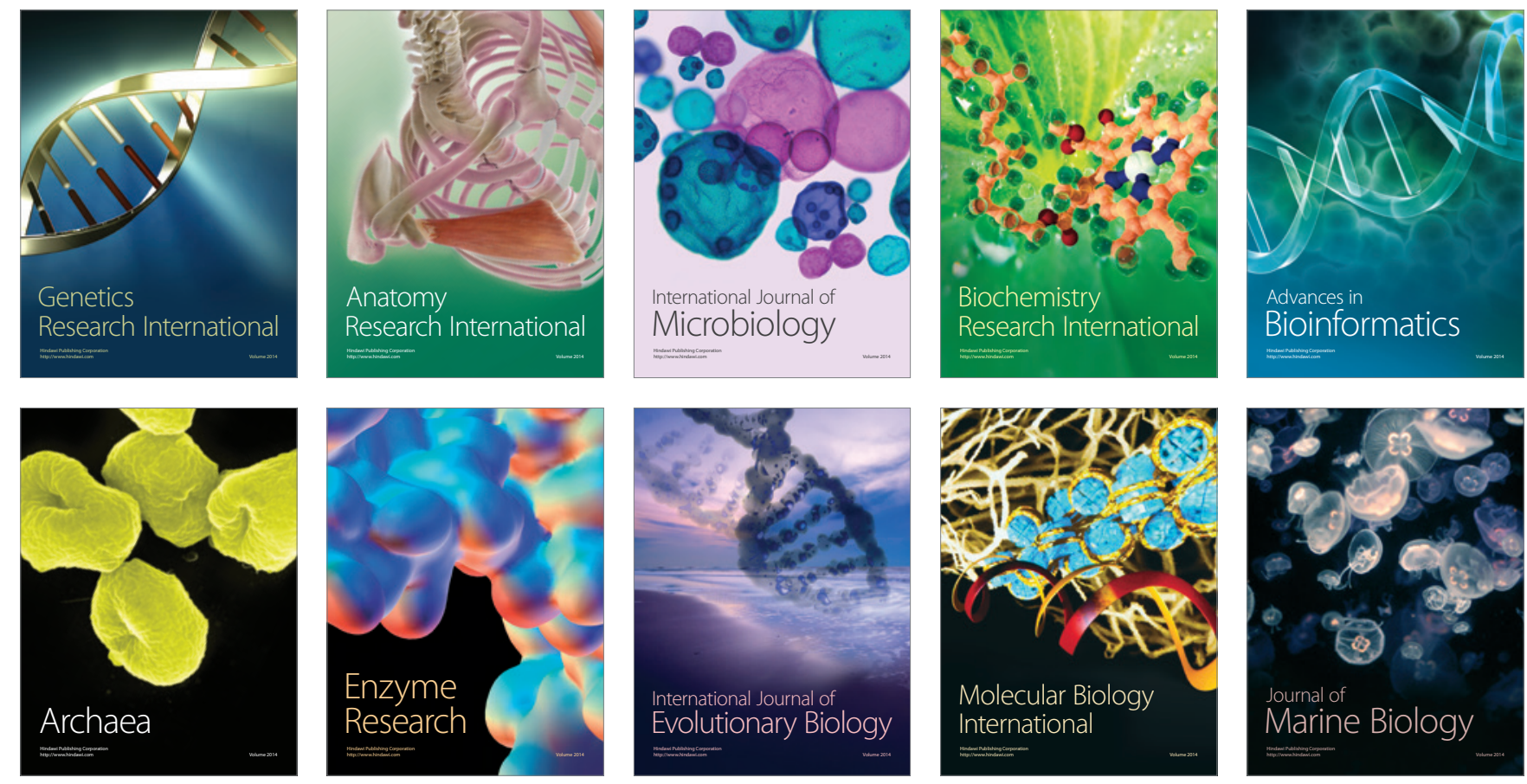